\title{
A comparative study on the regulating characteristics of flue gas temperature at SCR inlet under different reformed schemes of economizer
}

\author{
Y.J. Liao, Y.X. Yu \\ Electric Power Science Research Institute of Guangdong Power Grid Co., Ltd., Guangzhou, Guangdong, \\ China \\ L.W. Sun, J.H. Fan \\ School of Energy and power Engineering, North China Electric power University, Baoding, Hebei, China
}

\begin{abstract}
One 600MW unit in a power plant in Guangdong Province was taken as the study subject to contrastively analyze four different smoke temperature lifting schemes through thermodynamic calculation. The result indicate the non-feasibility of the feed water bypass scheme and the economizer exit water bypass recycling scheme due to the inadequate regulating ability; When the required SCR entrance smoke temperature ranges within $0 \sim 40^{\circ} \mathrm{C}$, the economizer smoke bypass scheme shows good regulating ability however the exhaust gas temperature rises, calling for measures e.g. low temperature economizer retrofit to counteract the effect that exhaust gas temperature rises decreasing boiler efficiency. The economizer staging retrofit scheme shows significant smoke temperature regulating ability despite the influence of reserved space and retrofit cost. When the removed area occupies less than $50 \%$ of the original economizer, SCR entrance smoke temperature ranges within $0 \sim 40^{\circ} \mathrm{C}$, ensuring normal operation under high load and the exhaust gas temperature is not so high that the boiler operation economy is affected .
\end{abstract}

KEYWORD: catalyst; SCR denitration efficiency; Ammonia escape rate; SCR entrance temperature; Optimize control

\section{INTRODUCTION}

Selective catalytic reduction (SCR) is widely used in coal-fired power plants to lower NOx emission due to the high denitration efficiency and the mature technology (Feng J.K., 2003). However when the SCR denitration system is in operation, the economizer exit smoke temperature is lower than SCR minimum allowable temperature, resulting in the denitration efficiency decreasing and even SCR out of service, which is a general problem in domestic power plants. To solve this, economizer retrofitting schemes have been applied to raise SCR entrance smoke temperature and denitration system operation rate. There have been not many contrastive studies on the principle characteristics of different gas regulating schemes and the effect of different schemes on boiler efficiency is short of discussion.

In the light of the low SCR entrance temperature of one $600 \mathrm{MW}$ unit under low boiler load, the effect and reason on lifting SCR entrance smoke temperature under $50 \%-70 \%$ THA conditions of four schemes were contrastively studied through thermodynamic calculation to raise an optimum smoke temperature lifting scheme, ensuring SCR entrance temperature always higher than that required for efficient operation, providing practical solution for lowering ammonia escape rate and alleviating problems e.g. air preheater blocking.

\section{INTRODUCTION TO THE RESEARCH SUBJECT}

One 600MW sub-critical coal-fired generating unit is taken as the research subject in this paper. The all steel framed $\pi$ type boiler is made by Mitsubishi Heavy Industries, equipped with a tangentially firing mode, the control cycle, a single reheat system, a balanced ventilated furnace, and the dry slag extraction device. The denitration system uses high ash type selective catalytic reduction technology.

According to the actual operating conditions, there are about 20 hours during which the boiler load is about $300 \mathrm{MW}$ and SCR entrance smoke temperature ranges within $300^{\circ} \mathrm{C} \sim 320^{\circ} \mathrm{C}$, lower than the optimum reaction temperature of SCR catalyst $\left(340^{\circ} \mathrm{C} \sim 380^{\circ} \mathrm{C}\right)$ and the SCR denitration efficiency is relatively low. To meet some certain denitration efficiency request, extra ammonia injection raises denitration cost, ammonia escape rate and the problem e.g. air preheater blocking.

Reducing ammonia injection amount results in the increase of $\mathrm{NO}_{\mathrm{x}}$ emission and contaminating the environment, which may also lead to $\mathrm{NO}_{\mathrm{x}}$ fine, rais- 
ing denitration cost. Therefore, to reach the optimum reaction temperature range and ensure efficient SCR operation, it is important to raise SCR entrance smoke temperature under low boiler load.

Table 1. The main parameters of catalyst.

\begin{tabular}{cccc}
\hline & $\begin{array}{c}\text { Design temperature } \\
\text { Maximum running } \\
\text { temperature }\end{array}$ & ${ }^{\circ} \mathrm{C}$ & 320 \\
operating & ${ }^{\circ} \mathrm{C}$ & 420 \\
temperature & & \\
& $\begin{array}{c}\text { minimum running } \\
\text { temper-ature }\end{array}$ & ${ }^{\circ} \mathrm{C}$ & 300 \\
\hline denitration efficiency & $\%$ & $>80$ \\
ammonia escap & $(\mu \mathrm{L} / \mathrm{L})$ & $<3$ \\
$\mathrm{SO}_{2} / \mathrm{SO}_{3}$ conversion ratio & $\%$ & $<1$ \\
pressure loss of catalyst & $\mathrm{Pa}$ & $<1100$ \\
catalyst Chemical life & $\mathrm{h}$ & 24000 \\
catalyst mechanical life & year & 10 \\
\hline
\end{tabular}

Table 2. The design on the parameters of the Inlet flue gain the denitrification system.

\begin{tabular}{lll}
\hline parameter & unit & data \\
concentration of fly ash & $\mathrm{g} / \mathrm{Nm} 3$ & 35 \\
$\mathrm{NOx}$ & $\mathrm{mg} / \mathrm{m} 3$ & 400 in design \\
$\mathrm{SO}_{2}$ & $\mathrm{mg} / \mathrm{m} 3$ & 1500 \\
$\mathrm{SO}_{3}$ & $\mathrm{mg} / \mathrm{m} 3$ & 18 \\
\hline
\end{tabular}

\section{ANALYSIS ON SMOKE TEMPERATURE LIFTING SCHEMES}

\subsection{Smoke temperature lifting schemes and calculation methods}

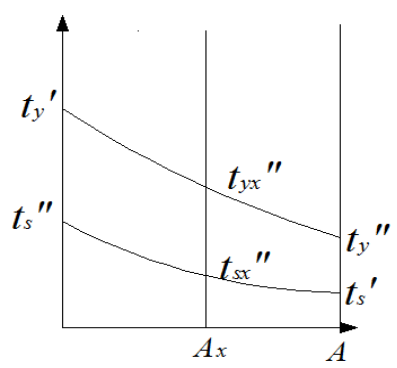

Fig.1 The temperature change of hot and cold fluid in the economizer with counter current arrangement

To lift SCR entrance smoke temperature, four schemes are applied, i.g. economizer feed water bypass scheme, economizer gas bypass scheme, economizer feed water bypass recycling scheme and economizer staging retrofit scheme, in which the area above sampling point at economizer exit is $A_{x}$ with the calculation model of smoke temperature and water temperature in economizer A established to study the principle characteristics of lifting smoke temperature. The temperature variation of the cold and hot fluid in the economizer is shown in Fig.1. The original economizer area is $A$ and Equation1 depicts the relationship of smoke temperature and water temperature:

$$
t_{y}^{\prime \prime}-t_{s}^{\prime}=\left(t_{y}^{\prime}-t_{s}^{\prime \prime}\right) e^{-\mu k A}
$$

where $t_{y}{ }^{\prime}$ and $t_{y}{ }^{\prime \prime}$ are smoke temperature at the original economizer entrance and exit; $t_{s}{ }^{\prime}$ and $t_{s}{ }^{\prime \prime}$ and water temperature at the original economizer entrance and exit; $\mu=1 / \mathrm{q}_{\mathrm{m} 1} / \mathrm{c}_{1}-1 / \mathrm{q}_{\mathrm{m} 2} / \mathrm{c}_{2} ; k$ is the heat transfer coefficient and $A$ is the area of the original economizer

The heat balance relationship is described as:

$Q_{A}=3.6 \times K \times A \times \Delta t_{m}=D \times c_{p} \times\left(t_{s}^{\prime \prime}-t_{s}^{\prime}\right)$

where $\Delta t_{m}$ is the mean temperature difference of the original economizer; $c_{p}$ is the constant-pressure specific heat of water; $D$ is the actual boiler load.

$$
\Delta t_{m}=-\frac{\Delta t^{\prime}}{\mu k A}\left(e^{-\mu k A}-1\right)=-\frac{\left(t_{y}^{\prime}-t_{s}^{\prime \prime}\right)}{\mu k A}\left(e^{-\mu k A}-1\right)
$$

The area above the sampling point at staged economizer A exit is Ax and the relationship of the smoke temperature and water temperature is shown in Equation 4:

$$
t_{y x}^{\prime \prime}-t_{s x}^{\prime \prime}=\left(t_{y}^{\prime}-t_{s}^{\prime \prime}\right) e^{-\mu k A_{x}}
$$

where $t_{y x}{ }^{\prime \prime}$ is the smoke temperature at A exit; $t_{s x}{ }^{\prime \prime}$ is the water temperature at A exit;

According to the heat balance equation5, the heat exchange of A $Q_{A x}$ is:

$$
Q_{A x}=3.6 \times K \times A_{x} \times \Delta t_{m x}=D \times c_{p} \times\left(t_{s}^{\prime \prime}-t_{s x}^{\prime \prime}\right)
$$

where $\Delta t_{m x}$ is the mean temperature difference of A, as calculated in Equation6:

$$
\Delta t_{m x}=-\frac{\Delta t^{\prime}}{\mu k A_{x}}\left(e^{-\mu k A_{x}}-1\right)=-\frac{\left(t_{y}^{\prime}-t_{s}^{\prime \prime}\right)}{\mu k A_{x}}\left(e^{-\mu k A_{x}}-1\right)
$$

$t_{y}{ }^{\prime}, t_{y}{ }^{\prime \prime}, t_{s}{ }^{\prime}, t_{s}{ }^{\prime \prime}, c_{p}$ and $\mu$ are then calculated based on the boiler thermodynamic calculation and Equation (1), (2) and (3)

According to Equation (5) and (6), the relationship between A exit water temperature and the area is:

$$
t_{s x}^{\prime \prime}=t_{s}^{\prime \prime}+\frac{3.6 \times\left(t_{y}^{\prime}-t_{s}^{\prime \prime}\right)}{c_{p} \times D \times \mu} \times\left(e^{-\mu k A_{x}}-1\right)
$$

By combining (4) and (7), the relationship between Ax and the exit smoke temperature tyx" is:

$$
t_{y x}^{\prime \prime}=t_{s}^{\prime \prime}+\frac{3.6 \times\left(t_{y}^{\prime}-t_{s}^{\prime \prime}\right)}{c_{p} \times D \times \mu} \times\left(e^{-\mu k A x}-1\right)+\left(t_{y}^{\prime}-t_{s}^{\prime \prime}\right) \times e^{-\mu k A x}
$$

It is clear that $t_{y x}$ " increases as $A_{x}$ decreases, indicating certain smoke temperature regulating ability of the scheme, capable of adjusting SCR entrance smoke temperature to the optimum catalyst reaction temperature range.

\subsection{Smoke temperature lifting schemes and calculation methods}

SCR entrance smoke temperature decreases as the load falls, thus it is reasonable to select the typical $50 \% \mathrm{THA}, 60 \% \mathrm{THA}$ and $70 \% \mathrm{THA}$ conditions, where the corresponding SCR entrance smoke temperature is $301{ }^{\circ} \mathrm{C}, 312^{\circ} \mathrm{C}$ and $328^{\circ} \mathrm{C}$, for analysis of the smoke temperature regulating ability of every scheme. All the other calculation conditions of every scheme are the same. 
The regulation characteristics of the economizer gas bypass scheme under 50\% THA, 60\% THA and $70 \%$ THA load are shown in Fig.2. At 50\% THA condition, when the bypass flue gas share rises from 0 to $50 \%$ (controlled by the bypass flue gas damper), SCR entrance smoke temperature rises by $39.5^{\circ} \mathrm{C}$ $\left(60 \% \mathrm{THA}, 38.5^{\circ} \mathrm{C}\right.$ and $\left.70 \% \mathrm{THA}, 44^{\circ} \mathrm{C}\right)$, capable of adjusting the smoke temperature. However the required flue area at $50 \%$ condition is relatively large compared to the small space at economizer entrance, indicating that from the perspective of technology, it is difficult to realize.

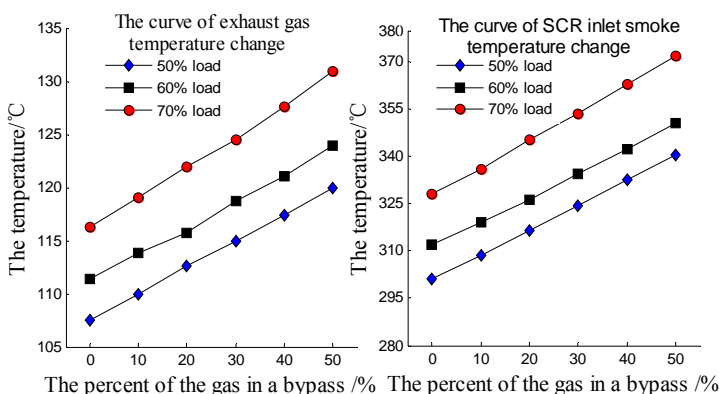

Fig.2 The curve on the relationship which is between the main variables and the percent of the gas in a bypass under the Given load.

The regulation characteristics of the economizer feed water bypass under 50\% THA, 60\% THA and $70 \%$ THA load are shown in Fig. 3 . At $50 \%$ condition, when the bypass feed water share rises from 0 to $70 \%$ (controlled by adjusting the economizer bypass flow share), SCR entrance smoke temperature rises by $15^{\circ} \mathrm{C}\left(60 \%\right.$ THA, $13{ }^{\circ} \mathrm{C}$ and $\left.70 \%, 14^{\circ} \mathrm{C}\right)$. When the bypass feed water share is adjusted to $70 \%$, SCR entrance smoke temperature does rise however it is not feasible to operate the unit at $70 \%$ bypass feed water because at this point the economizer exit water temperature is beyond the saturation temperature $317.12^{\circ} \mathrm{C}$.

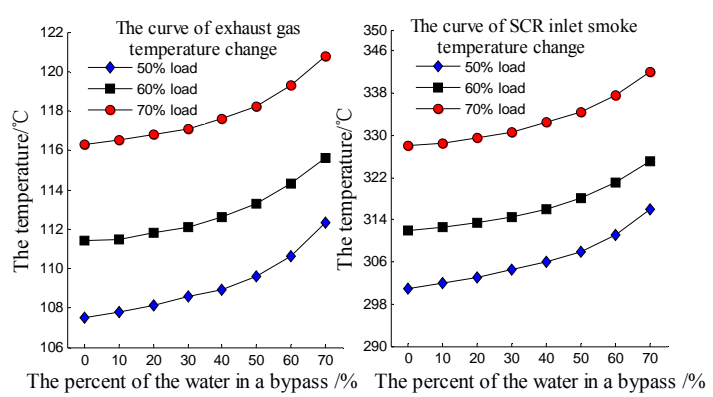

Fig.3 The characteristic curve of the water supply bypass for the economizer

The regulation characteristics of the economizer exit water bypass recycling scheme under 50\% THA, $60 \%$ THA and 70\% THA load are shown in Fig.4. At $50 \%$ THA condition, when the bypass water share rises from 0 to $80 \%$ (controlled by adjusting the exit water share), there is not big variation detected in every main variable. SCR entrance temperature rises by $5.5^{\circ} \mathrm{C}\left(60 \% \mathrm{THA}, 4.3^{\circ} \mathrm{C}\right.$ and $\left.70 \%, 4.9^{\circ} \mathrm{C}\right)$, indicating inadequate smoke temperature regulating ability and incapability to reach the optimum reaction temperature. This scheme is easy to realize yet it costs much to install the circulating pump in the bypass pipes.

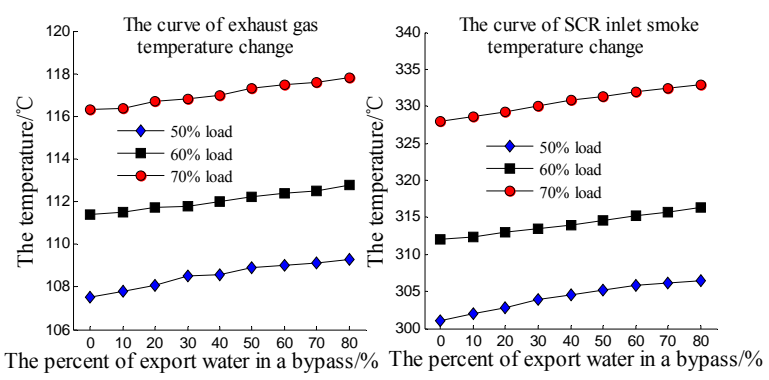

Fig.4 The curve on the relationship which is between the main variables and the percent of the export water in a bypass under the given load
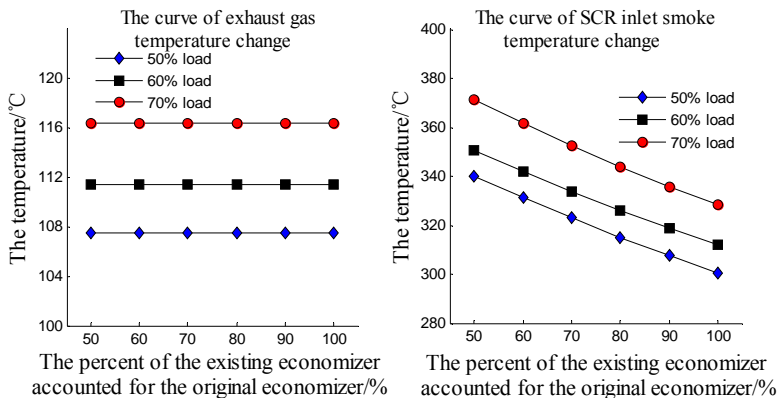

Fig.5 The curve on the relationship which is between the main variables and the economizer $-\mathrm{A}$ accounted for the percent of the original economizer under the Given load

The regulation characteristics of the economizer staging retrofit scheme under 50\% THA, 60\% THA and $70 \%$ THA are shown in Fig.5. When the removed area of the original economizer rises from 0 to $50 \%$, SCR entrance smoke temperature rises by $39.4^{\circ} \mathrm{C}\left(60 \% \mathrm{THA}, 38.5^{\circ} \mathrm{C}\right.$ and $\left.70 \% \mathrm{THA}, 43^{\circ} \mathrm{C}\right)$, indicating good regulating ability.

However moving 50\% the original economizer area to SCR flue pipe requires transformation of SCR pipe because of unreserved space for economizer B, which from the perspective of technology, is difficult to realize. When the unit is in operation under high boiler load, whether the entrance temperature after economizer retrofit is beyond the maximum allowable temperature $\left(430^{\circ} \mathrm{C}\right.$, listed in Table 2) needs to be considered. Removing $50 \%$ of the share contributes to the entrance temperature rising significantly from $364^{\circ} \mathrm{C}$ to $405^{\circ} \mathrm{C}$ thermodynamically calculated under BMCR condition and it is still under $430^{\circ} \mathrm{C}$, indicating SCR normal operation under high boiler load. 
By comparatively calculation analysis of four smoke temperature regulating schemes, the economizer feed water bypass scheme and economizer exit water bypass recycling scheme is incapable due to the limited SCR entrance smoke temperature lifting effect, whose main reason lies in the small water hear transfer $\mathrm{Q}$ variation. As depicted in Equation9:

$Q_{A}=3.6 \times A \times K \Delta t_{m}=D \times c_{p} \times\left(t_{s}^{\prime \prime}-t_{s}^{\prime}\right)=\varphi \times B_{j} \times\left(h_{y}^{\prime}-h_{y}^{\prime \prime}+\Delta \alpha h_{l k}^{0}\right)$

Taking logarithm and calculate the total differential of both sides of the equality sign and taking $K \Delta t_{m}$ as a whole:

$\frac{d Q}{Q}=\frac{d A}{A}+\frac{d\left(K \Delta_{m}\right)}{K \Delta_{m}}=\frac{d \varphi}{\varphi}+\frac{d h_{y}^{\prime}}{h_{y}^{\prime}-h_{y}^{\prime \prime}-\Delta d h_{l k}^{0}}-\frac{d h_{y}^{\prime \prime}}{h_{y}^{\prime}-h_{y}^{\prime \prime}-\Delta d h_{k k}^{0}}+\frac{d\left(\Delta d h_{k k}^{0}\right)}{h_{y}^{\prime}-h_{y}^{\prime \prime}-\Delta d h_{l k}^{0}}$

where $A, D, c_{p}, t_{s}^{\prime}, \varphi, B_{j}, h_{y}{ }^{\prime}, \Delta \alpha$ and $h_{l k}{ }^{0}$ are constants. The relationship between the heat transfer $\mathrm{Q}$ and the product of the heat coefficient $K$ and the average heat transfer temperature difference is:

$\frac{d Q}{Q}=\frac{d\left(K \Delta t_{m}\right)}{K \Delta t_{m}}=-\frac{d h_{y}^{\prime \prime}}{h_{y}^{\prime}-h_{y}^{\prime \prime}-\Delta \alpha h_{l k}^{0}}$

As depicted in Equation 11, Q increases in proportion to $K \Delta t_{m}$ and in inverse proportion to economizer exit smoke temperature $h_{y}{ }^{\prime \prime}$. The variation relation between $K \Delta t_{m}$ and the bypass share under $70 \%$ THA condition in the four schemes is shown in Figure8. As depicted in Equation 11, the decreasing amplitude of the heat transfer Q is different in every scheme with the change of the bypass share. The Q decreasing amplitude of the economizer feed water bypass and the economizer exit water recycling bypass scheme is relatively small, indicating small $h_{y}{ }^{\prime \prime}$ increasing amplitude and inadequate smoke temperature regulating ability of these two schemes. The economizer gas bypass scheme has a large $h_{y}{ }^{\prime \prime}$ increasing amplitude and significant regulating ability.

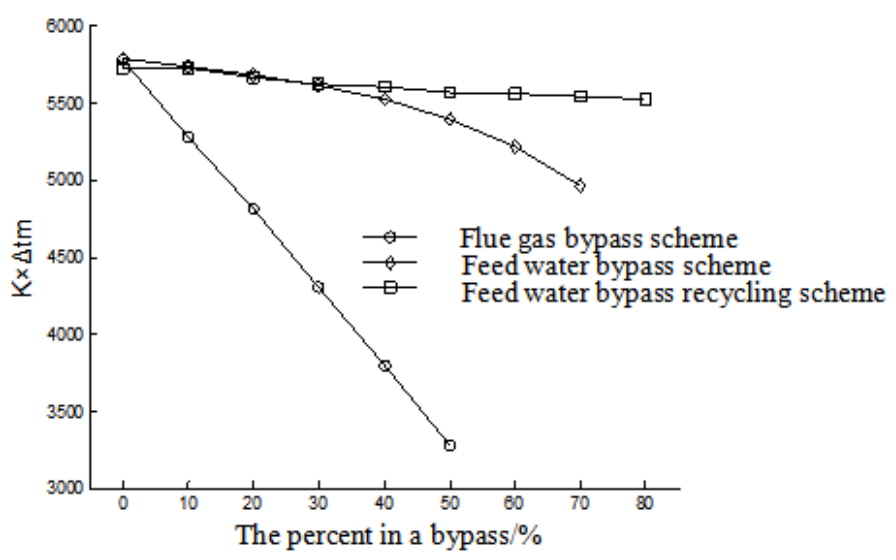

Fig.6 The relationship between mean temperature difference $\Delta \mathrm{tm}$ and heat transfer coefficient $\mathrm{K}$ of the economizer and the bypass share for each scheme

Increasing SCR entrance smoke temperature leads to the increase of exhaust gas temperature and the boiler efficiency falling. In a general power plant boiler, the efficiency falls by $1 \%$ when the exhaust gas temperature rises by $10-15^{\circ} \mathrm{C}$. Due to the limited
SCR smoke temperature regulating ability of the economizer feed water bypass scheme and the economizer feed water bypass recycling scheme, the increase of the exhaust gas temperature is no more than $5{ }^{\circ} \mathrm{C}$ while in the economizer gas bypass scheme, as shown in Figure4, the exhaust gas temperature rises by $12.5^{\circ} \mathrm{C}\left(60 \% \mathrm{THA}, 12.5^{\circ} \mathrm{C}\right.$ and $70 \%$ THA, $14.6^{\circ} \mathrm{C}$ ) under $50 \%$ THA condition, significantly affecting the boiler operation economy, calling for measures e.g. low temperature economizer retrofit to counteract the effect that exhaust gas temperature rises decreasing boiler efficiency. The economizer staging retrofit scheme not only fits the request of denitration device smoke temperature, but not raises the exhaust gas temperature due to the constant heated area, because of which the heat exchange at the flue gas side and the water side in the economizer stays constant thus SCR exit smoke temperature, i.g. the exhaust gas temperature does not change, and the boiler operation economy is not affected. This is the preferred smoke temperature lifting scheme.

\section{CONCLUSION}

(1) The economizer feed water bypass scheme and the economizer exit water recycling scheme is not feasible due to the inadequate smoke temperature regulating ability. Also the feed water bypass scheme is easy to result in boiling water and vaporization in the pipes, threatening the boiler safety and economy. The exit water recycling scheme calls for extra water circulation pumps raising the cost.

(2) The economizer gas bypass scheme is capable of adjusting SCR entrance smoke temperature by a range of $40^{\circ} \mathrm{C}$ with a good regulating ability. However this scheme calls for measures e.g. low temperature economizer retrofit to counteract the effect that exhaust gas temperature rises decreasing boiler efficiency.

(3) In the economizer staging retrofit scheme, to achieve the optimum catalyst reaction temperature range, under 50THA condition, more than $50 \%$ of the original economizer area is to be removed(60\% THA, $40 \%$ and 70\% THA, 20\%). The size of the removed area directly affect SCR smoke temperature lifting amplitude. After the transformation, when the boiler is in operation under a high load, whether the entrance temperature is beyond the maximum allowable temperature should be taken into consideration.

(4) The economizer staging retrofit scheme shows significant smoke temperature regulating ability despite the influence of reserved space and retrofit cost, ensuring normal operation under high load and the exhaust gas temperature is not so high that the boiler operation economy is affected. 


\section{REFERENCES}

Feng J.K., Shen Y.T., Yang R.C., 2003.The principle and calculation of Boiler (The third Edition) [M].Beijing: Science Press, China.

Gao y., Luan T., Cheng K., et al. 2011. The experimental study on selective catalytic reduction honeycomb catalyst industry $[\mathrm{J}]$. Chinese Journal of Electrical Engineering (35): 21-28.

Huang W.J., Dai S.F., Ai C.M., et al. 2015. Discussion on total load SCR denitrification control technology for coal-boiler on power station [J]. Energy saving technology33(2):189193.

Schaub G. Unruh D. Al. 2003. Kinetic analysis of selective catalytic NOx reduction (SCR) in a catalytic filter[J]. Chemical Engineering and Processing5(42): 365-371.

Shen B.X., Zhao N., Liu T. 2011. Simulation study on the catalytic reduction of the flue gas denitrification by selective catalytic reduction[J]. Chinese Journal of Electrical Engineering $(08)$ : 31-37.

Xu X.,Ying J.,Wang X.L. 2010. Performance test of selective catalytic reduction of flue gas denitrification system in coal fired power plant $[\mathrm{J}]$. Journal of power engineering30(6) : 439-443.

Yang J.G., Fan L.A., Zhao H., Mou W.B., et al. 2014. Improving the coordination and optimization of the smoke temperature in the catalyst reaction efficiency [J]. Chinese Journal of Electrical Engineering34(14): 2245-2250.

Zhou X.Q.,Yang C. 2007. Removal of nitrate reactor mathematical model and Simulation of selective catalytic reduction[J]. Journal of Chongqing University(Natural Science Edition)(06) : 39-43. 